\title{
Accurate Measurements of Aerosol Hygroscopic Growth over a Wide Range in Relative Humidity
}

\author{
Grazia Rovelli, ${ }^{\dagger}{ }^{\ddagger}$ Rachael E. H. Miles, ${ }^{\dagger}$ Jonathan P. Reid, ${ }^{*}{ }^{\dagger}$ and Simon L. Clegg ${ }^{\S}$ \\ ${ }^{\dagger}$ School of Chemistry, University of Bristol, Bristol BS8 1TS, U.K. \\ ${ }^{\ddagger}$ Department of Earth and Environmental Sciences, University of Milano-Bicocca, 20124 Milan, Italy \\ ${ }^{\S}$ School of Environmental Sciences, University of East Anglia, Norwich NR4 7TJ, U.K.
}

Supporting Information

\begin{abstract}
Using a comparative evaporation kinetics approach, we describe a new and accurate method for determining the equilibrium hygroscopic growth of aerosol droplets. The time-evolving size of an aqueous droplet, as it evaporates to a steady size and composition that is in equilibrium with the gas phase relative humidity, is used to determine the time-dependent mass flux of water, yielding information on the vapor pressure of water above the droplet surface at every instant in time. Accurate characterization of the gas phase relative humidity is provided from a control measurement of the evaporation profile of a droplet of know equilibrium properties, either a pure water droplet or a sodium chloride droplet. In combination, and by comparison with simulations that account for both the heat and mass transport governing the droplet evaporation

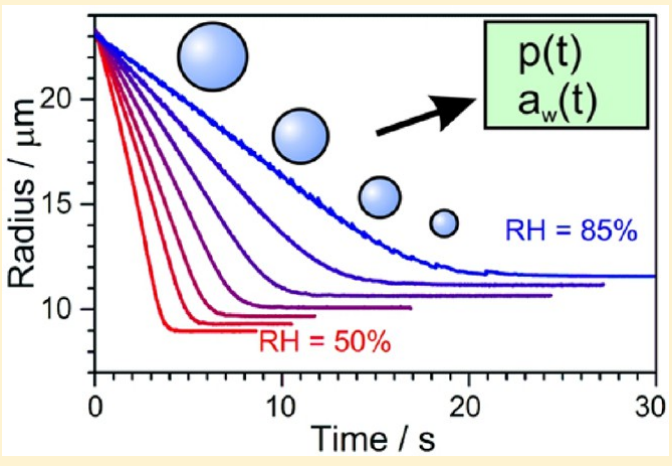
kinetics, these measurements allow accurate retrieval of the equilibrium properties of the solution droplet (i.e., the variations with water activity in the mass fraction of solute, diameter growth factor, osmotic coefficient or number of water molecules per solute molecule). Hygroscopicity measurements can be made over a wide range in water activity (from $>0.99$ to, in principle, $<0.05$ ) on time scales of $<10 \mathrm{~s}$ for droplets containing involatile or volatile solutes. The approach is benchmarked for binary and ternary inorganic solution aerosols with typical uncertainties in water activity of $< \pm 0.2 \%$ at water activities $>0.9$ and $\sim \pm 1 \%$ below $80 \% \mathrm{RH}$, and maximum uncertainties in diameter growth factor of $\pm 0.7 \%$. For all of the inorganic systems examined, the time-dependent data are consistent with large values of the mass accommodation (or evaporation) coefficient $(>0.1)$.
\end{abstract}

\section{INTRODUCTION}

Quantifying the equilibrium hygroscopic growth of aerosol is important for understanding the liquid water content and size distributions of atmospheric aerosol and for modeling their optical properties, for predicting cloud droplet number and size distribution following the activation of cloud condensation nuclei ( $\mathrm{CCN}$ ), and for determining the partitioning of semivolatile organic compounds (SVOCs) in the condensed aerosol phase. ${ }^{1,2}$ The capacity for aerosols to absorb water can also influence their deposition in the respiratory track on inhalation, potentially influencing the impact of aerosols on health. ${ }^{3}$ The uncertainties in understanding these processes provide an incentive to improve the characterization of aerosol hygroscopicity. As an example, cloud parcel models have shown that the cloud droplet number can vary by as much as $50 \%$ depending on the strength of the assumed hygroscopic growth as saturation is approached. ${ }^{4}$

Rigorous thermodynamic models for calculating the hygroscopic response of mixed component aerosol have been developed on the basis of bulk phase and aerosol phase measurements of the equilibrium response of binary solutions of a single solute and water. ${ }^{5,6}$ When combined with treatments of solution density and surface tension, accurate predictions of the variation in equilibrium particle size with relative humidity are possible. ${ }^{7,8}$ To represent the equilibrium properties of solutions containing the myriad of potential organic compounds found in the atmosphere, it is often necessary to resort to functional group activity models that require consideration of the interactions between electrolytes and organic species., 10 However, there is also a requirement to provide models of hygroscopic growth that are tractable in computational models of atmospheric chemistry, radiative transfer, and climate models. To achieve this, models such as $\kappa$-Köhler theory have been developed to represent the hygroscopicity of aerosol particles using a single value of $\kappa$, with a higher value representing more hygroscopic aerosol $(>0.5$ for ammonium sulfate and sodium chloride) and a lower value representing less hygroscopic aerosol $\left(<0.05\right.$ for insoluble fatty acids). ${ }^{11,12}$ Measurements of $\kappa$ have been made for aerosols varying in complexity from binary component solution aerosol through to the complex inorganic-aqueous mixtures found in the atmosphere. $^{13-15}$

Received: April 26, 2016

Revised: June 6, 2016

Published: June 10, 2016 
At a fundamental level, both the thermodynamic factors governing hygroscopic growth and the kinetics of condensation must be better quantified to represent the aerosol microphysics under-pinning the partitioning of water between the gas and particle phases. A number of significant uncertainties must be addressed to improve the microphysical description of water partitioning. There can be significant differences between hygroscopic growth measurements made on different instruments. ${ }^{16}$ Further, estimates of the critical supersaturation for CCN activation inferred from $\kappa$ values determined from measurements under subsaturated conditions are often inconsistent with values determined directly. ${ }^{16,17}$ The gasparticle partitioning of volatile organic compounds (VOCs) and SVOCs, and co-condensation with water during CCN activation is poorly constrained and has been largely ignored, not only effecting predictions of particle growth in the atmosphere but also introducing ambiguity into measurements of hygroscopic growth. ${ }^{2}$ Although the molecular complexity of secondary organic aerosol (SOA) precludes an accurate treatment of hygroscopic growth that explicitly accounts for each compound individually, empirical correlations that seek to exploit dependencies on average measures of composition (e.g., the variation of $\kappa$ with $\mathrm{O}: \mathrm{C}$ ratio) are often poorly defined and, at best, appropriate only for specific SOA precursors and environmental conditions. ${ }^{13-15}$ The slow deliquescence and low solubility of some organic components present challenges in interpreting measurements of hygroscopic growth. ${ }^{18}$ Liquidliquid phase separation into internal mixtures of hydrophobic and hydrophilic phases in mixed component aerosol remains a challenge in predicting equilibrium properties. ${ }^{19,20}$ The extent of the depression of surface tension by surface active organic components and the interplay of surface and bulk partitioning in determining the critical supersaturation remains difficult to resolve. $^{21,22}$ Finally, the kinetics of water, VOC and SVOC condensation are often poorly determined with few quantitative measurements of the mass accommodation coefficients of organic species in particular. ${ }^{23-25}$

To address the challenges in quantifying hygroscopicity for aerosols of complex composition, refinements in laboratory and field instrumentation, and improved frameworks for representing hygroscopicity, are required. ${ }^{26,27}$ Hygroscopic growth measurements must be made up to water activities close to the dilute limit, ideally as high as 0.999. Such high water activities $\left(a_{\mathrm{w}}\right)$ are required for measurements to be directly relevant to $\mathrm{CCN}$ activation ${ }^{28}$ and to place tighter constraints on the equilibrium solution compositions required to underpin the development of predictive models. ${ }^{29}$ Building on our previous preliminary report, ${ }^{32}$ we present here a more general and wide ranging characterization of a new method for deriving hygroscopic growth curves for coarse mode particles over a wide water activity range (in principle from dry conditions to $>0.999$ ). We concentrate on aerosol droplets of well-known composition and containing well-characterized electrolytes to benchmark the technique. Growth curve measurements can be determined rapidly and accurately, potentially opening up the possibility of mapping hygroscopic response for a large number of organic components of SOA and, indeed, complex mixtures and SOA samples directly. In section 2 we review the experimental technique and the analyses methods used before presenting measurements of hygroscopic growth for binary solutions of sodium chloride, ammonium sulfate, sodium sulfate, and sodium nitrate in section 3 . We also consider the accuracy of the approach by exploring the ability of the instrument to resolve small changes in hygroscopic growth for mixed-salt containing aerosol droplets.

\section{EXPERIMENTAL SECTION}

Comparative kinetics measurements for the quantification of the hygroscopicity of aerosols using the cylindrical electrodynamic balance (EDB) experimental setup have been described in previous publications. ${ }^{32-34}$ In this section, an overview of the instrument and of the determination of hygroscopic properties from measurements on multiple droplets is presented, extending our previous work over a wider range in water activity. The adopted treatments for refractive index and density are also introduced.

2.1. Cylindrical EDB. The EDB technique allows the levitation of a single charged aerosol droplet inside an electrical field. Single droplets are generated on-demand from a solution with known initial concentration by applying a pulse voltage to the filled reservoir of a microdispenser (Microfab MJ-ABP-01), placed just outside one of the walls of the EDB chamber. Between droplet generation events, a smaller constant pulse voltage is applied to the microdispenser to continuously flush some solution through its tip, thus assuring that no evaporation of solvent and no variation of the solution concentration can occur from measurement to measurement. The initial radius of the droplets once trapped varies from about 18 to $25 \mu \mathrm{m}$. Before entering the trapping chamber, a net charge is imparted to every droplet by means of a high-voltage induction electrode. Within $100 \mathrm{~ms}$ of its generation, the droplet is tightly confined in the center of the electrodynamic field inside the EDB chamber. An ac signal is applied to the cylindrical electrodes and a dc offset is superimposed, to balance the gravitational and drag forces on the trapped droplet. The cylindrical configuration of the electrodes results in a steep gradient in the potential in the trapping region, guaranteeing a strong confinement of the droplets, ${ }^{35}$ with little harmonic oscillation in the position of the particle that is characteristic of other electrode configurations.

The droplet is confined within a gas flow, which results from the mixing of wet and dry nitrogen flows. It is possible to change the ratio between these two flows by means of mass flow controllers (MKS 1179A) and this allows the control of the relative humidity $(\mathrm{RH})$ of the gas phase that surrounds the droplet. The temperature of the chamber is controlled by recirculating a mixture of water and ethylene glycol $(50 \% \mathrm{v} / \mathrm{v})$ from a thermostatic water bath (Julabo, F32-HE) through the lid and the bottom of the chamber. The accessible temperature range is -25 to $+50{ }^{\circ} \mathrm{C}$. In this study all the measurements were performed at $20^{\circ} \mathrm{C}$.

The trapped droplet is illuminated by light from a green laser $(\lambda=532 \mathrm{~nm})$. The resulting elastic scattering pattern is collected every $10 \mathrm{~ms}$ over a range of solid angles centered at $45^{\circ}$ by means of a CCD camera and is used to determine the radius of the droplet with the simplified geometrical optics approximation approach, ${ }^{36}$ using Equation 1:

$$
a=\frac{\lambda}{\Delta \theta}\left(\cos (\theta / 2)+\frac{m \sin (\theta / 2)}{\sqrt{1+m^{2}-2 m \cos (\theta / 2)}}\right)^{-1}
$$

where $a$ is the droplet radius, $\lambda$ is the incident wavelength, $\theta$ is the central viewing angle, $\Delta \theta$ is the angular separation between the fringes in the scattering pattern, and $m$ is the refractive 
index of the droplet. The error associated with the radius determination with this approach is $\pm 100 \mathrm{~nm}$.

The refractive index of the evaporating droplets is not constant because the solute concentration increases as water evaporates. This variation of the refractive index with time must be taken into account for an accurate determination of the droplet radii. At first, during the data acquisition, $m$ is set constant at 1.335, the value for pure water at $532 \mathrm{~nm}$. In a postacquisition analysis step, the radii data are corrected by taking into account the variation of the refractive index with mass fraction of solute ( $\mathrm{mfs}$ ) by applying the molar refraction mixing rule, ${ }^{37}$ which has been demonstrated to be the best mixing rule to describe the refractive index for a number of inorganic systems. ${ }^{38}$ The molar refraction $(R)$ of a component $i$ is defined as

$$
R_{i}=\frac{\left(m_{i}^{2}-1\right) M_{i}}{\left(m_{i}^{2}+2\right) \rho_{i}}=\frac{\left(m_{i}^{2}-1\right) V_{i}}{\left(m_{i}^{2}+2\right)}
$$

where $M_{i}$ is the compound's molecular mass and $\rho_{i}$ is its pure melt density. The ratio of molecular mass to liquid density is equivalent to the molar volume of pure $i, V_{i}$. The molar refraction for the solution, $R$, is the sum of the molar refractions of each component, including all solutes and water, weighted by their mole fractions $\left(x_{i}\right)$ :

$$
R=\sum_{i} x_{i} R_{i}
$$

In this study, the variation in solution densities with mass fraction of solute and the pure solute melt densities are taken from the work of Clegg and Wexler. ${ }^{39}$ The melt densities are extrapolations from high-temperature measurements compiled and evaluated by Janz. ${ }^{40}$ For ease of data processing, the density data are represented as a function of the square root of the mass fraction of solute $\left(\mathrm{mfs}^{0.5}\right)$ and fitted with a polynomial curve (order ranging from fourth to seventh) so that the residual from the fit is $<0.005 \mathrm{~g} \mathrm{~cm}^{-3}$ across the whole mfs range. This density dependence is then used to constrain a least-squares fit of the tabulated data of solution refractive index for solute concentrations below the solubility limit, ${ }^{41}$ to the functional dependence of the molar refraction mixing rule. The only fit parameter is the value of the pure component refractive index of the molten salt. From this fit, the value of the refractive index of the solution, $m$, at any solute concentration can then be found from eq 4 by solving for $m$ using the $\mathrm{mfs}$, the estimated density of the solution at this composition $\rho$, a mole fraction weighted molecular mass $M$, and the estimated molar refraction of the solution.

$$
R=\frac{\left(m^{2}-1\right) M}{\left(m^{2}+2\right) \rho}
$$

The procedure used to take into account the variation in refractive index during the evaporation is the following. There is a time period $(\sim 0.1 \mathrm{~s})$ between droplet generation and the first determination of size when the droplet is in transit into the trapping region. ${ }^{32,33}$ Thus, the initial size of the droplet is estimated with a linear extrapolation of the $a^{2}$ vs time plot to $t=$ $0 \mathrm{~s}$; the initial solute mass fraction and density of solute solution at $t=0 \mathrm{~s}$ and at this droplet size are known from the prepared solution. ${ }^{33}$ The elastic light scattering data are first analyzed with $m=1.335$ to yield an initial estimate of the variation in radius with time, also providing a first estimate of the variation of the solute concentration and of the solution density during the evaporation. A set of corrected refractive indices for the droplet solution at every time step is then calculated on the basis of the change in size using the molar refraction mixing rule (eqs 2-4). These corrected refractive indices at each time point are then used to fit a new set of corrected radii with eq 1 . This procedure is repeated for the new set of corrected radii until the refractive indices and radii values converge, typically after $2-3$ iterations.

One key feature of this experimental setup is the presence of two microdispensers that can be operated sequentially, thus allowing the generation of aerosol droplets with different chemical compositions in rapid succession. This feature allows comparative kinetics measurements, which consist of levitating a sequence of droplet pairs; one probe droplet (either water or a well-characterized salt solution, such as $\mathrm{NaCl}$ ), followed by one sample droplet containing the solution of interest. Typically, these kinds of comparative kinetic measurements consist of a series of at least ten pairs of probe and sample droplets. The evaporation kinetics of the probe droplets (when water) or their equilibrated size (when aqueous $\mathrm{NaCl}$ ) are used to determine the gas phase $\mathrm{RH}$, which is key information for the interpretation of the evaporation profile of the unknown sample droplet, as will be discussed in sections 2.2 and 2.3.

2.2. Modeling Aerosol Droplet Evaporation Kinetics. The mass and heat transport equations from Kulmala and coworkers ${ }^{42}$ can be used to model the evaporation and condensation kinetics of water or other volatile species from/ to aerosol droplets. For the evaporation case, the mass flux from the droplet $(I)$ depends on the concentration gradient of the evaporating species (water in this work) from the droplet surface to infinite distance. We have considered the influence of droplet charge on evaporation rates in previous work, ${ }^{32}$ showing it to have negligible impact at the imbalance of positive and negative ions induced in the droplets studied in these experiments. ${ }^{44}$ The mass transfer enhancement resulting from the flowing gas surrounding the droplet is accounted for by the inclusion of a Sherwood number (Sh) scaling of the mass flux. ${ }^{33,43}$ The thermophysical parameters that appear in the mass flux treatment and their uncertainties have been thoroughly discussed in previous publications. ${ }^{32,34,45,46}$ The resulting expression for the mass flux is the following:

$$
I=-2 \operatorname{Sh} \pi a\left(S_{\infty}-a_{\mathrm{w}}\right)\left[\frac{R T_{\infty}}{M \beta_{M} D p^{0} T_{\infty} A}+\frac{a_{w} L^{2} M}{K R \beta_{T} T_{\infty}^{2}}\right]^{-1}
$$

where $S h$ is the Sherwood number, $S_{\infty}$ is the saturation ratio of water in the surrounding gas phase (also referred to as $\mathrm{RH}$ in this work), $a_{\mathrm{w}}$ is the water activity in the droplet solution, $R$ is the ideal gas constant, $T_{\infty}$ is the gas phase temperature, $L$ is the latent heat of vaporisation, and $M$ is the molar mass of water. $\beta_{M}$ and $\beta_{T}$ are the transition correction factors for mass and heat, respectively; these corrections are very small for the coarse mode droplet sizes considered here and this will be demonstrated when we consider the sensitivity of the thermodynamic measurement to the value of the mass accommodation coefficient. $D$ is the diffusion coefficient of water in the gas phase, $p^{0}$ is the saturation vapor pressure of water, $A$ is the Stefan flow correction, and $K$ is the thermal conductivity of the gas phase.

As an example of the data acquired during droplet evaporation, a series of seven $\left(\mathrm{NH}_{4}\right)_{2} \mathrm{SO}_{4}$ solution droplets evaporating into different RHs at $20^{\circ} \mathrm{C}$ are shown in Figure $1 \mathrm{~A}$ 

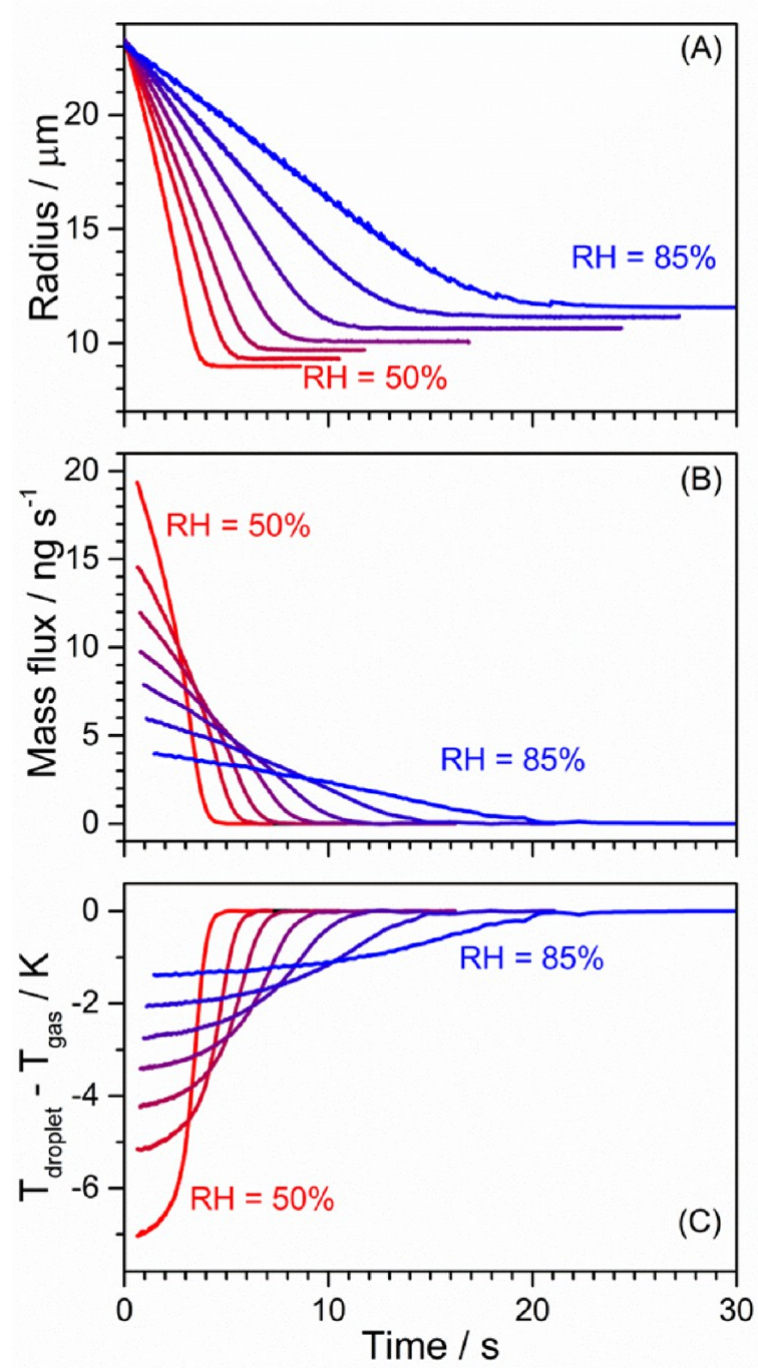

Figure 1. (A) Measured radii $(\mu \mathrm{m})$ of seven $\left(\mathrm{NH}_{4}\right)_{2} \mathrm{SO}_{4}$ solution droplets (initial $\mathrm{mfs}$ of about 0.05 ) evaporating into different $\mathrm{RHs}$ at $20{ }^{\circ} \mathrm{C}$. Red to blue curves indicate increasing $\mathrm{RH}$ in the gas phase at approximately equally spaced intervals in $\mathrm{RH}$, from $\sim 50 \%$ (red) to $\sim 85 \%$ (blue) $\mathrm{RH}$. The method for determining the $\mathrm{RH}$ exactly is described in section 2.3. (B) For the same droplets, the calculated mass flux $\left(\mathrm{ng} \mathrm{s}^{-1}\right)$ from the droplet is plotted against time. (C) Variation in time of the difference between the temperature $(\mathrm{K})$ of the droplet surface $\left(T_{\text {droplet }}\right)$ and the gas phase $\left(T_{\text {gas }}\right)$, calculated according to eq 9.

over the range from $50 \%$ to $85 \% \mathrm{RH}$. The initial mass fraction of the starting solution was 0.05 , and the initial radii of the seven different droplets varied from 23.0 to $23.3 \mu \mathrm{m}$. The total amount of water that evaporates from each droplet depends on the gas phase $\mathrm{RH}$ and the final equilibrated radius is such that the $a_{\mathrm{w}}$ in the droplet matches the RH in the surrounding gas phase. The evaporation rate increases with decreasing $\mathrm{RH}$ because the mass flux is proportional to the difference between the solution water activity and the RH (eq 5). As shown in Figure 1B, the mass flux is at its highest value for every droplet at the beginning of the evaporation because $S_{\infty}-a_{\mathrm{w}}$ is at its maximum. Over time, the evaporation slows down and the mass flux decreases until the droplet is in equilibrium with the gas phase and $I$ is zero. The evaporation time extends from $5 \mathrm{~s}$ at $50 \% \mathrm{RH}$ to about $25 \mathrm{~s}$ at $85 \% \mathrm{RH}$.
2.3. Aerosol Hygroscopic Growth from Comparative Kinetic Measurements in the EDB. The mass and heat transport model presented in section 2.2 is used to compare the evaporation kinetics of probe and sample droplets and to estimate aerosol hygroscopic growth curves from data of the form shown in Figure 1, as follows. The procedure is described below and also outlined in the Supporting Information. First, the probe droplet evaporation profile is analyzed to determine the gas phase $\mathrm{RH}$, which is expressed as a percentage throughout this work; note that $a_{\mathrm{w}}$ is always represented as a fractional value. The probe droplet can be either pure water or a $\mathrm{NaCl}$ solution. Davies et al. ${ }^{32}$ demonstrated the validity of both methods in the determination of the $\mathrm{RH}$ in this kind of comparative kinetic measurements and also estimated the errors on the RH retrieved in both cases.

When a pure water droplet is used as a probe, its experimental radius-squared versus time evaporation profile is compared to simulated evaporation curves at different $\mathrm{RH}$, calculated using eq 4. The mean squared difference (MSD) between the experimental profile and each calculated curve is estimated and the $\mathrm{RH}$ corresponding to the curve with the lowest MSD is selected. In this case, the lower and upper values of the $\mathrm{RH}$ come from uncertainties in the thermophysical parameters $D( \pm 6 \%)$ and $K( \pm 2 \%)^{46}$ in eq 5 and are given by

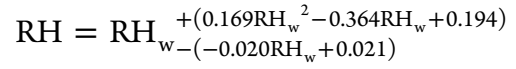

When a $\mathrm{NaCl}$ solution with known initial concentration is used as a probe, the equilibrated size of the droplet after water evaporation may be used to determine the water activity in the solution, and therefore the $\mathrm{RH}$ in the gas phase. To do this, the thermodynamic Extended Aerosol Inorganics Model (EAIM $)^{5,6,47}$ (http://www.aim.env.uea.ac.uk/) is used to calculate how water activity and density change with the solution composition during evaporation and to predict the equilibrated radius of the droplet after water evaporation has ended at a given $\mathrm{RH}$. For the relationship between water activity and $\mathrm{NaCl}$ concentration, the model is based upon the critical review of Archer, ${ }^{48}$ and electrodynamic balance measurements of several authors (see Table 1 of Clegg et al. ${ }^{49}$ ). Densities of aqueous $\mathrm{NaCl}$ (up to and including the hypothetical pure liquid salt) were calculated using the equations of Clegg and Wexler. ${ }^{39}$

The lowest $\mathrm{RH}$ value that can be determined with this method is limited by the efflorescence $\mathrm{RH}$ of $\mathrm{NaCl}$, which is around $48 \%$. If this equilibrated size method is used, the uncertainties in $\mathrm{RH}$ arise from the accuracy with which the equilibrated radius is known $( \pm 100 \mathrm{~nm})$ and the uncertainty in the determination of the initial droplet size at $t=0 \mathrm{~s}\left({ }_{-100}^{+150} \mathrm{~nm}\right)$, which corresponds to an uncertainty of less than $0.8 \%$ of the dry radius for the droplet sizes considered in this work. In this case, the lower and upper values of the $\mathrm{RH}$ are expressed as

$$
\mathrm{RH}=\mathrm{RH}_{\mathrm{eq}}+\left(0.0175 \mathrm{RH}_{\mathrm{eq}}{ }^{2}-0.0005 \mathrm{RH}_{\mathrm{eq}}+0.017\right)
$$

Using a pure water droplet as a probe of $\mathrm{RH}$ is preferable as the equilibrated size method includes a further uncertainty from the initial $\mathrm{NaCl}$ solution concentration. Nevertheless, $\mathrm{NaCl}$ was used as a probe for measurements at $\mathrm{RH}<80 \%$ because the associated uncertainties on the RH determined with water as a probe droplet would be too significant. Uncertainties in the simulation of pure water evaporation become increasingly large below this $\mathrm{RH}$ due to uncertainties in the thermophysical parameters $D$ and $K$ and because of the approximation that are 
needed in the expression of the vapor pressure of water at the droplet surface (discussed further in section 3.1).

According to eq 6, the $\mathrm{RH}$ can be determined with an uncertainty smaller than ${ }_{-0.3 \%}^{+0.33 \%}$ for $\mathrm{RH}$ values above $90 \%$ when pure water is used as a probe. At $50 \% \mathrm{RH}$, the error in \% $\mathrm{RH}$ associated with the determination of $\mathrm{RH}$ with the equilibrated size method is ${ }_{-1.5 \%}^{+1.2 \%}$, according to eq 7 . Knowing the $\mathrm{RH}$ with such accuracy is crucial for an accurate application of the kinetics model presented in section 2.2. The uncertainty of commercial $\mathrm{RH}$ probes is typically between $\pm 1 \%$ and $\pm 3 \%$ in the $\mathrm{RH}$ range $10-90 \%$ and it usually dramatically increases for $\mathrm{RH}$ values above $90 \%$. Both the methods used in this work to retrieve the gas phase $\mathrm{RH}$ are associated with smaller uncertainties in the $\mathrm{RH}$ determination, especially for measurements at high $\mathrm{RH}$. The $\mathrm{RH}$ of the gas phase in the EDB trapping chamber is kept constant during the evaporation measurements, but slight fluctuations in $\mathrm{RH}$ can sometimes be observed. However, the $\mathrm{RH}$ is monitored frequently with probe droplets during the entire duration of the experiments (5-15 min for ten pairs of sample and probe droplets, depending on the $\mathrm{RH}$ at which the measurements are taken). The magnitude of these fluctuations is typically smaller or comparable to the uncertainty associated with the $\mathrm{RH}$ determination $(<0.2-0.3 \%$ above $80 \% \mathrm{RH}$ with water as a probe, $<0.5-0.6 \%$ below $80 \%$ $\mathrm{RH}$ with $\mathrm{NaCl}$ as a probe).

Once the gas phase $\mathrm{RH}$ is known, eq 5 can be rearranged and solved for $a_{\mathrm{w}}$ to calculate the water activity in the droplet at each point in time during evaporation. The particle radius is measured, $S_{\infty}$ is determined from the probe droplet, and the mass flux $I$ can be calculated from the collected radius versus time plot, whereas all the other quantities are known. For the calculation of mass flux, the radii data must be converted to particle mass values and the density of the droplet is thus needed. The parametrization of density as a function of squarerooted mass fraction of solute has been discussed in section 2.1. The initial solute $\mathrm{mfs}$ at $t=0 \mathrm{~s}$ is known from the prepared solution and the initial droplet density can be determined. Therefore, considering the measured variation in volume due to the evaporation of water, the $\mathrm{mfs}$ and density for every measured point during evaporation can be calculated. Knowing how the mass of the droplet varies in time, the mass flux ( $I=$ $\mathrm{d} m / \mathrm{d} t)$ can be calculated as the slope of the mass versus time calculated curve and eq 5 can be used to determine how the $a_{\mathrm{w}}$ varies in the droplet with time. Over each time step, the droplet can be considered to be homogeneous in composition; the diffusional mixing time is estimated to be $0.01 \mathrm{~s}$ for a droplet with a radius of $15 \mu \mathrm{m}$ and assuming a water diffusion coefficient of $2 \times 10^{-9} \mathrm{~m}^{2} \mathrm{~s}^{-1}$.

In addition, from the measured radii data and knowing the density of the droplet at each instant, the radial growth factor $\left(\mathrm{GF}_{\mathrm{r}}\right)$ and moles of water per moles of solute $\left(n_{\text {water }} / n_{\text {solute }}\right)$ can be calculated for each measured radii during the evaporation of the sample droplet. Coupling these last quantities with the information about the solution water activity, hygroscopicity curves for the sample compounds can be reported as $G F_{\mathrm{r}}$ vs $a_{\mathrm{w}}$, $n_{\text {water }} / n_{\text {solute }}$ vs $a_{\mathrm{w}}$, and mfs vs $a_{\mathrm{w}}$. To obtain robust hygroscopic data from these comparative kinetics measurements, all curves contain data averaged over at least ten sample droplets. To average the hygroscopicity data calculated from the evaporation of multiple droplets, all the obtained $G F_{\mathrm{r}}, n_{\text {water }} / n_{\text {solute, }}$ and $\mathrm{mfs}$ values are separated into $a_{\mathrm{w}}$ bins $\left(0.03-0.005 a_{\mathrm{w}}\right.$ intervals, depending on the $\mathrm{RH}$ at which the measurements are taken) and the data points attributed to each bin are then averaged.
The final averaged curves for each compound will be presented in section 3, unless otherwise specified.

2.4. Materials. Sodium chloride, ammonium sulfate (both $\geq 99.5 \%$, Sigma-Aldrich), sodium nitrate, and sodium sulfate ( $\geq 99.5 \%$ and $\geq 99 \%$ respectively, Fisher Scientific) solutions were prepared with an initial known mass fraction of solute of $\sim 0.05$ for all compounds. To make measurements at higher initial $a_{\mathrm{w}}$ values, solutions with an initial known mfs of $\sim 0.005$ were also prepared. The gas flow in the EDB chamber was nitrogen (BOC, oxygen-free).

\section{RESULTS AND DISCUSSION}

\subsection{Full Hygroscopicity Curves from Measurements} into Different Gas Phase RHs. In deriving hygroscopic growth relationships from droplet evaporation measurements, we must first consider in more detail the accuracy of the framework presented in section 2.2. The mass transport of water from the droplet to the gas phase during evaporation is coupled to heat transfer, with the latent heat of vaporisation associated with this phase change removed from the droplet. The heat flux from the droplet is greatest when the evaporation rate of water is fastest and, when it is not balanced by the heat flux from the surrounding environment to the droplet, the condensed phase cools down. This temperature depression of the droplet has to be considered because the vapor pressure of water at the surface of the droplet is temperature dependent and directly influences the evaporation rate. In the derivation of Kulmala and co-workers, ${ }^{42}$ the dependence of the vapor pressure of the evaporating species at the droplet surface $\left(p_{\mathrm{a}}\right)$ on temperature is calculated from the Clausius-Clapeyron equation. The exponential term in this expression is approximated with the first-order term in a Taylor series expansion:

$$
\begin{aligned}
p_{\mathrm{a}} & =a_{\mathrm{w}} p^{0}\left(T_{\mathrm{gas}}\right) \exp \left(\frac{L M\left(T_{\mathrm{droplet}}-T_{\mathrm{gas}}\right)}{R T_{\text {droplet }} T_{\mathrm{gas}}}\right) \\
& \approx a_{\mathrm{w}} p^{0}\left(T_{\mathrm{gas}}\right)\left(1+\frac{L M\left(T_{\text {droplet }}-T_{\mathrm{gas}}\right)}{R T_{\text {droplet }} T_{\mathrm{gas}}}\right)
\end{aligned}
$$

where $p^{0}\left(T_{\text {gas }}\right)$ is the saturation vapor pressure at the temperature of the gas phase $\left(T_{\text {gas }}\right)$ and $T_{\text {droplet }}$ is the temperature at the droplet surface.

This approximated expression for the temperature dependence of the vapor pressure of water is only accurate when the difference between the droplet and gas phase temperatures is less than $\sim 3{ }^{\circ} \mathrm{C}$; beyond this threshold value the approximation with the Taylor series expansion results in an underestimation of the value of the exponential larger than $1 \%$ at $25^{\circ} \mathrm{C},{ }^{42}$ with a subsequent underestimation of $p_{\mathrm{a}}$. Consequently, when the droplet temperature depression is large, the vapor pressure of water at the surface of the droplet is increasingly underestimated. Therefore, the only measured points that can be used to reliably calculate the water activity in the evaporating sample droplet are those that satisfy this condition. $T_{\text {droplet }}-$ $T_{\text {gas }}$ can be estimated according to eq $9:^{42}$

$$
T_{\text {droplet }}-T_{\text {gas }}=-\frac{I L}{4 \pi \beta_{T} K a}
$$

Figure 1C shows the time dependence of the temperature difference $T_{\text {droplet }}-T_{\text {gas }}$ for the same seven $\left(\mathrm{NH}_{4}\right)_{2} \mathrm{SO}_{4}$ droplets as in the two previous panels. The initial temperature 
depression can reach $-7 \mathrm{~K}$ in correspondence to the fastest evaporation rates (at $50 \% \mathrm{RH}$ ), whereas for the three droplets evaporating into a higher $\mathrm{RH}$ (about $78 \%, 81 \%$, and $85 \%$, respectively) the calculated temperature depression is always less than $3 \mathrm{~K}$.

The effect of the droplet temperature depression on the estimated hygroscopic behavior of a sample compound retrieved from the measurements is shown in Figure 2. Panel
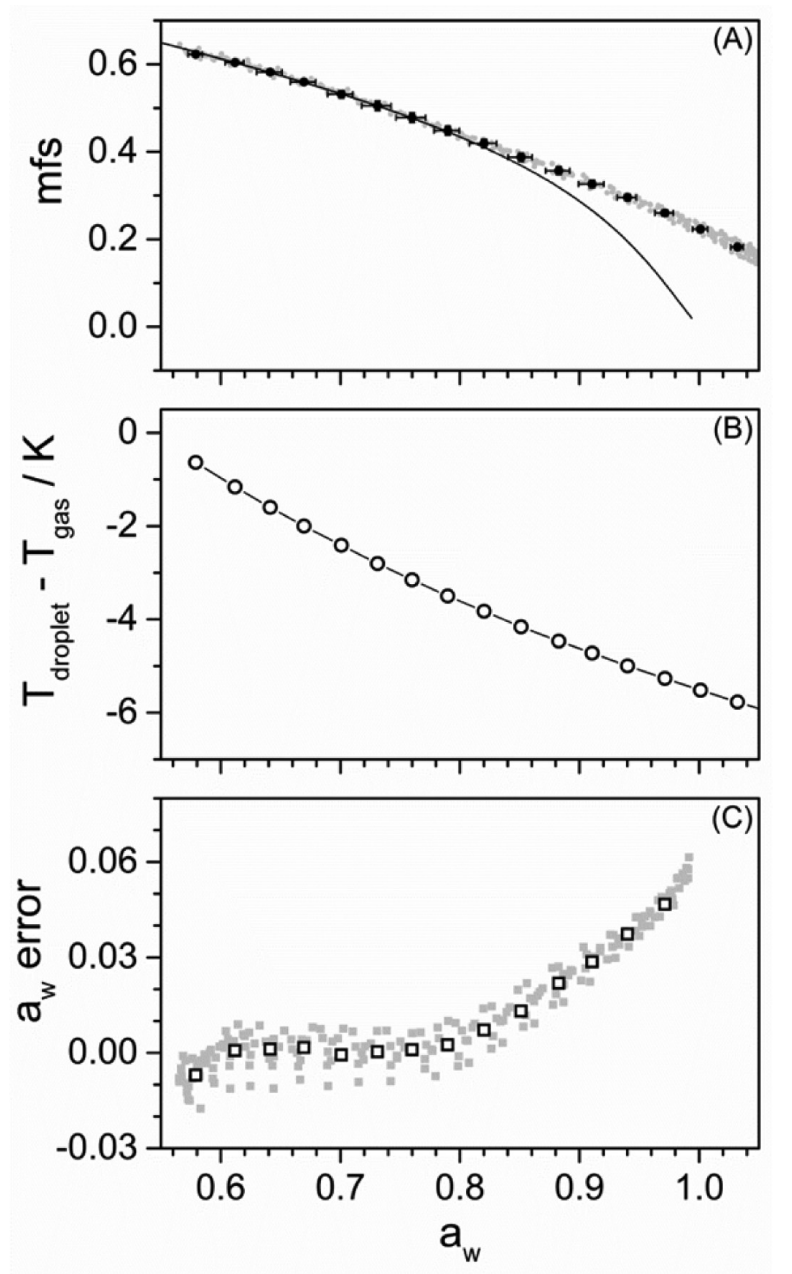

Figure 2. (A) Mass fraction of solute ( $\mathrm{mfs}$ ) vs $a_{\mathrm{w}}$ plot, calculated from the evaporation kinetics of $10\left(\mathrm{NH}_{4}\right)_{2} \mathrm{SO}_{4}$ droplets evaporating into $58 \% \mathrm{RH}$. Symbols: gray dots, data from each individual droplet; black dots, averaged curve calculated over the 10 droplet data set; solid line, $\mathrm{mfs}$ vs $a_{\mathrm{w}}$ for $\left(\mathrm{NH}_{4}\right)_{2} \mathrm{SO}_{4}$ calculated with the E-AIM model. (B) Difference in temperature between the droplet surface and the surrounding gas phase as a function of $a_{w}$, calculated with eq 9. (C) Absolute error in $a_{\mathrm{w}}$ relative to the reference E-AIM model values. Symbols: gray squares, error on $a_{\mathrm{w}}$ from each individual droplet; open black squares, error on $a_{\mathrm{w}}$ relative to the averaged $\mathrm{mfs}$ curve.

A presents the mfs versus $a_{\mathrm{w}}$ relationship obtained from a data set of ten $\left(\mathrm{NH}_{4}\right)_{2} \mathrm{SO}_{4}$ droplets evaporating at $58 \% \mathrm{RH}$. A very good agreement with the E-AIM model prediction can be observed for low $a_{\mathrm{w}}$ values, both for the averaged curve and for all the ten single droplets. For higher $a_{\mathrm{w}}$ values, which are derived from the measurements of fluxes at early evaporation times, the water activity calculated with eq 5 is overestimated and even assumes unrealistic values beyond 1. This arises because the corresponding droplet temperature depression
(Figure 2B) is larger in magnitude than the $-3 \mathrm{~K}$ threshold, which is satisfied only below a calculated $a_{\mathrm{w}}$ of 0.73 . The absolute error on the calculation of $a_{\mathrm{w}}$ is shown in Figure 2C. This $a_{\mathrm{w}}$ error was calculated as the difference between the experimental $a_{\mathrm{w}}$ calculated with eq 5 and the water activity calculated with the E-AIM model at a certain mfs value. For the averaged data, the absolute errors on the calculated $a_{\mathrm{w}}$ are very close to 0 at $a_{\mathrm{w}}$ values below 0.73 , whereas they reach values up to about 0.06 when $T_{\text {droplet }}-T_{\text {gas }}$ is of the order of -5 to $-6 \mathrm{~K}$.

As a consequence of this limitation in the kinetics framework, only a portion of about 0.2 in water activity of the mfs curve of a sample compound can be retrieved when measurements are taken into an $\mathrm{RH}$ at $50 \%$. As a consequence, evaporation measurements into at least three different RHs are need to determine a full curve from 0.5 to $>0.99 a_{\mathrm{w}}$. An example of this procedure is shown in Figure 3 for the determination of the

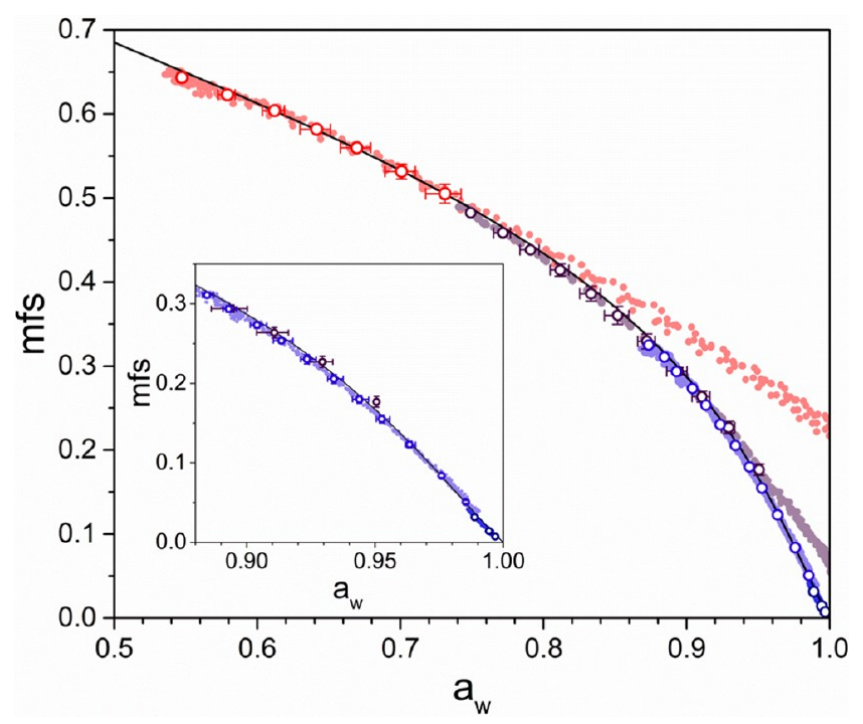

Figure 3. Retrieval of the full $\mathrm{mfs}$ vs $a_{\mathrm{w}}$ curve of ammonium sulfate from measurements into different RHs. Symbols: solid line, calculated $\mathrm{mfs}$ vs $a_{\mathrm{w}}$ curve from the E-AIM model; filled circles, individual data from all 10 droplets in each data set; open circles, averaged data for which the maximum $3 \mathrm{~K}$ droplet temperature depression condition is satisfied. Colors: red, purple, and light blue, droplets of $0.05 \mathrm{mfs}$ starting solution evaporating into a gas phase at $54 \%, 74 \%$, and $87.3 \%$ $\mathrm{RH}$, respectively; dark blue, $0.005 \mathrm{mfs}$ starting solution into a gas phase $90 \% \mathrm{RH}$. Note: error bars are smaller than the data point when not shown.

relationship between $a_{\mathrm{w}}$ and $\mathrm{mfs}$ for $\left(\mathrm{NH}_{4}\right)_{2} \mathrm{SO}_{4}$, in which EDB results are compared to the E-AIM model prediction (solid black line). Evaporation measurements with a starting solution of $\sim 0.05 \mathrm{mfs}$ were made into three different RHs (54\%, 74\%, and $87.3 \%)$. A fourth data set was collected at high $\mathrm{RH}(90 \%$, more clearly visible in the inset in Figure 3) using a solution with lower starting concentration $(\mathrm{mfs}$ of 0.005$)$ and therefore with a higher starting $a_{\mathrm{w}}(0.997)$. In this latter case, just a very small section of the mfs curve can be calculated: because the droplet had a very low initial concentration, it was not possible to keep it trapped until its $a_{\mathrm{w}}$ equilibrated with the surrounding $\mathrm{RH}$, as it undergoes an exceptionally large size change. The open circles represent data points averaged over ten droplets and have been considered acceptable only if the difference in temperature between the droplet and the gas phase is estimated to be smaller than the $3 \mathrm{~K}$ limit. In the background, data for all 
the ten droplets in the same four data sets are shown. All the data points can be accepted for the two data sets measured at high $\mathrm{RH}$, with the evaporation sufficiently slow to maintain a small droplet temperature depression, whereas just small portions of the data measured at $54 \%$ and $74 \% \mathrm{RH}$ can be accepted. The agreement with the $a_{\mathrm{w}} \mathrm{vs} \mathrm{mfs}$ curve calculated with the E-AIM model is very good for the points that lie within the $3 \mathrm{~K}$ threshold for the droplet temperature depression.

One of the interesting features of the comparative kinetics measurements in the cylindrical EDB is that hygroscopic growth curves can be measured up to very high $a_{\mathrm{w}}$ values $(>0.99)$. In Figure 4, the very high end for the measured $\mathrm{GF}_{r}$, $n_{\text {water }} / n_{\text {solute }}$ and $\mathrm{mfs}$ versus water activity plots are shown for $\left(\mathrm{NH}_{4}\right)_{2} \mathrm{SO}_{4}$ and are compared with simulations from the EAIM model (solid lines). In this case, the highest $a_{\mathrm{w}}$ reached with this averaged data set is 0.997 , corresponding to a $\mathrm{GF}_{\mathrm{r}}$ value of 6.22 (Figure 4A). For the calculation of the radial growth curve, the dry radius of the droplets is calculated from
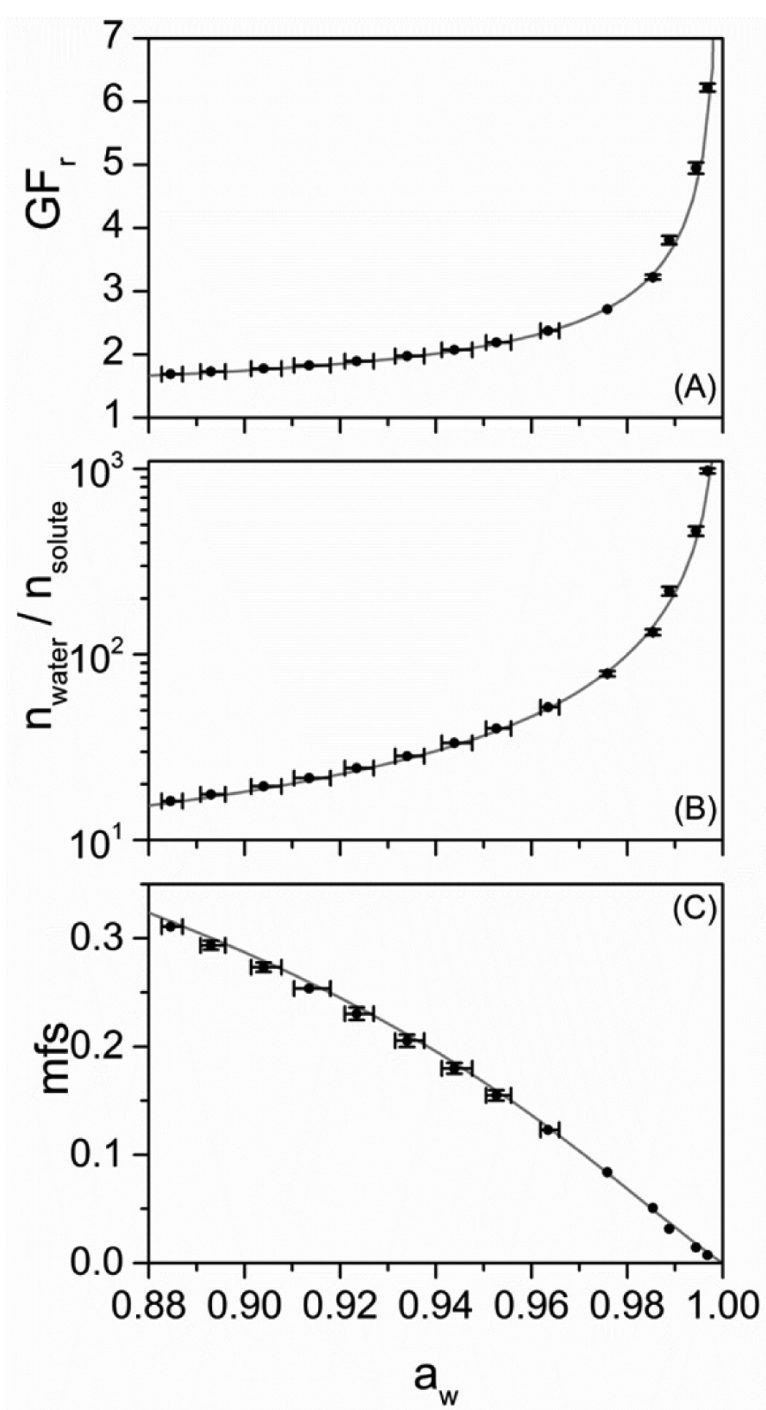

Figure 4. $\mathrm{GF}_{\mathrm{r}}, n_{\text {water }} / n_{\text {solute, }}$ and $\mathrm{mfs}$ for $a_{\mathrm{w}}$ values between 0.88 and 1 for $\left(\mathrm{NH}_{4}\right)_{2} \mathrm{SO}_{4}$. Symbols: filled circles, experimental data points averaged over a minimum of 10 droplets; solid lines, calculated curves from the E-AIM model. Note: error bars are smaller than the data point when not shown. the wet size at $t=0 \mathrm{~s}$, the concentration of the starting solution, and the density of crystalline ammonium sulfate $(1.77 \mathrm{~g}$ $\left.\mathrm{cm}^{-3}\right) .{ }^{41}$ In Figure 4B, at $a_{\mathrm{w}}=0.997$ the number of absorbed moles of water per moles of $\left(\mathrm{NH}_{4}\right)_{2} \mathrm{SO}_{4}$ inferred from the measurements is close to 1000 and the agreement between the measured value and the E-AIM model prediction is remarkable. If the mfs vs $a_{\mathrm{w}}$ plot is considered (Figure 4C), the lowest measured ammonium sulfate mass fraction is 0.005 at $a_{\mathrm{w}}=$ 0.997. It is also worth noting that not only is it possible to measure growth curves up to very high water activity values with this technique but also the accuracy on the calculated $a_{\mathrm{w}}$ is highest when the $\mathrm{RH}$ at which measurements are taken is high (>90\%), according to eqs 6 and 7. It should also be stressed that the growth curve is retrieved in a matter of seconds, potentially allowing accurate hygroscopic growth measurements for droplets containing volatile components, provided their vapor pressure is less than that of water.

3.2. Accuracy of Measurements. Hygroscopicity measurements on four well-characterized inorganic-aqueous systems $\left(\mathrm{NaCl}, \mathrm{Na}_{2} \mathrm{SO}_{4}, \mathrm{NaNO}_{3}\right.$, and $\left.\left(\mathrm{NH}_{4}\right)_{2} \mathrm{SO}_{4}\right)$ were performed to confirm the validity of the method over the range in $a_{\mathrm{w}}$ from 0.5 to 0.99 . The relationships between $\mathrm{mfs}$ and $a_{\mathrm{w}}$ for each solute are shown in Figure 5, compared with the corresponding prediction from the E-AIM model. The level of agreement obtained is excellent for all the systems studied. $\mathrm{Na}_{2} \mathrm{SO}_{4}$ was observed to crystallize during measurements at $a_{\mathrm{w}}$ $=0.57$, and therefore it was not possible to reach lower water activity values during the experiments. In addition, the systematic overpredictions of E-AIM between water activities of 0.75 and 0.85 and underpredictions at the lowest $a_{\mathrm{w}}$ are consistent with previous observations (see, for example, Figure 3 of Clegg et al. $^{49}$ ). It should be noted that the measurement for an aqueous sodium chloride droplet provides a consistency check of the approach for inferring the hygroscopicity from kinetics measurements. For control sodium chloride droplets, measurements of the final equilibrated size are used to infer the $\mathrm{RH}$ of the gas flow. This value is then used in the retrieval of the $\mathrm{mfs}$ data from the kinetic measurement at all intermediate nonequilibrated $a_{\mathrm{w}}$ values; in combination, this allows confirmation of the shape of the $\mathrm{mfs}$ vs $a_{\mathrm{w}}$ dependence at all intermediate water activities.

Osmotic coefficients, $\phi$, provide a convenient way to characterize the departure of solutes from ideality and can be determined from the equation

$$
\phi=-\frac{\ln \left(a_{\mathrm{w}}\right)}{M_{\mathrm{w}} m_{i} v_{i}}
$$

where $M_{\mathrm{w}}$ is the molecular weight of water, $m_{i}$ is the molality of the solute $i$, and $v_{i}$ is the stoichiometric coefficient of solute $i$. As the water activity tends to unity at zero solute molality, the osmotic coefficient should tend to 1 with the expected DebyeHückel limiting law behavior. In Figure 6 we report the dependence of the osmotic coefficient on solute molality for the four binary systems studied, providing a stringent examination of the retrieved hygroscopic behavior particularly at the dilute solution limit. As expected, the dependence of the osmotic coefficient on water activity leads to large uncertainties at low molality, a consequence of the large uncertainties in water activity in the early stages of evaporation (high mass flux) of dilute solution droplets. At molalities higher than $1 \mathrm{~mol} \mathrm{~kg}^{-1}$, the close agreement between the measured and modeled osmotic coefficients for all systems suggests that the 

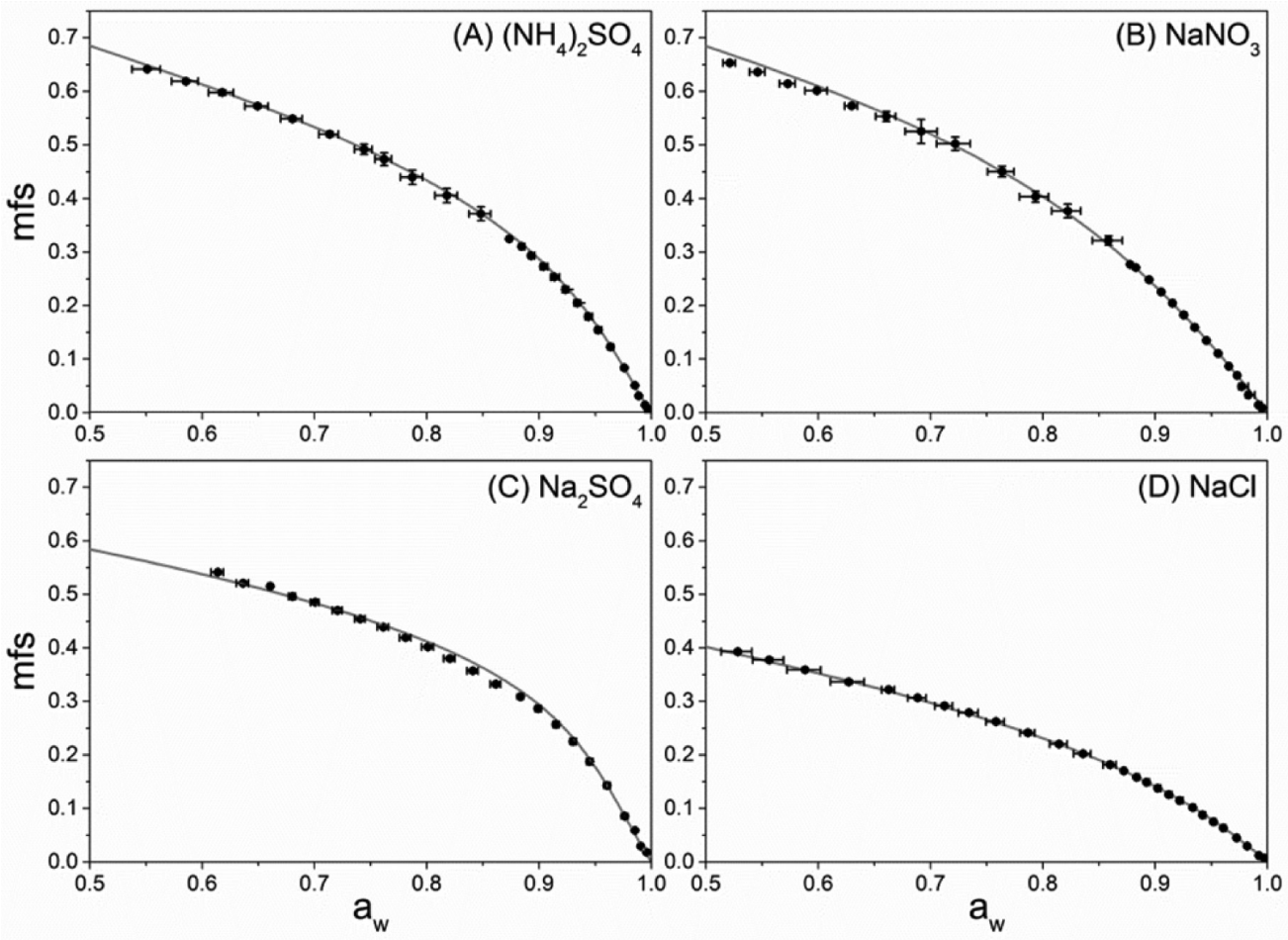

Figure 5. Measured mfs vs $a_{\mathrm{w}}$ plots for $\left(\mathrm{NH}_{4}\right)_{2} \mathrm{SO}_{4}, \mathrm{NaNO}_{3}, \mathrm{Na}_{2} \mathrm{SO}_{4}$, and $\mathrm{NaCl}$ (panels A-D). Symbols: filled circles, experimental data; solid lines, calculation from the E-AIM model. Note: error bars are smaller than the data point when not shown.
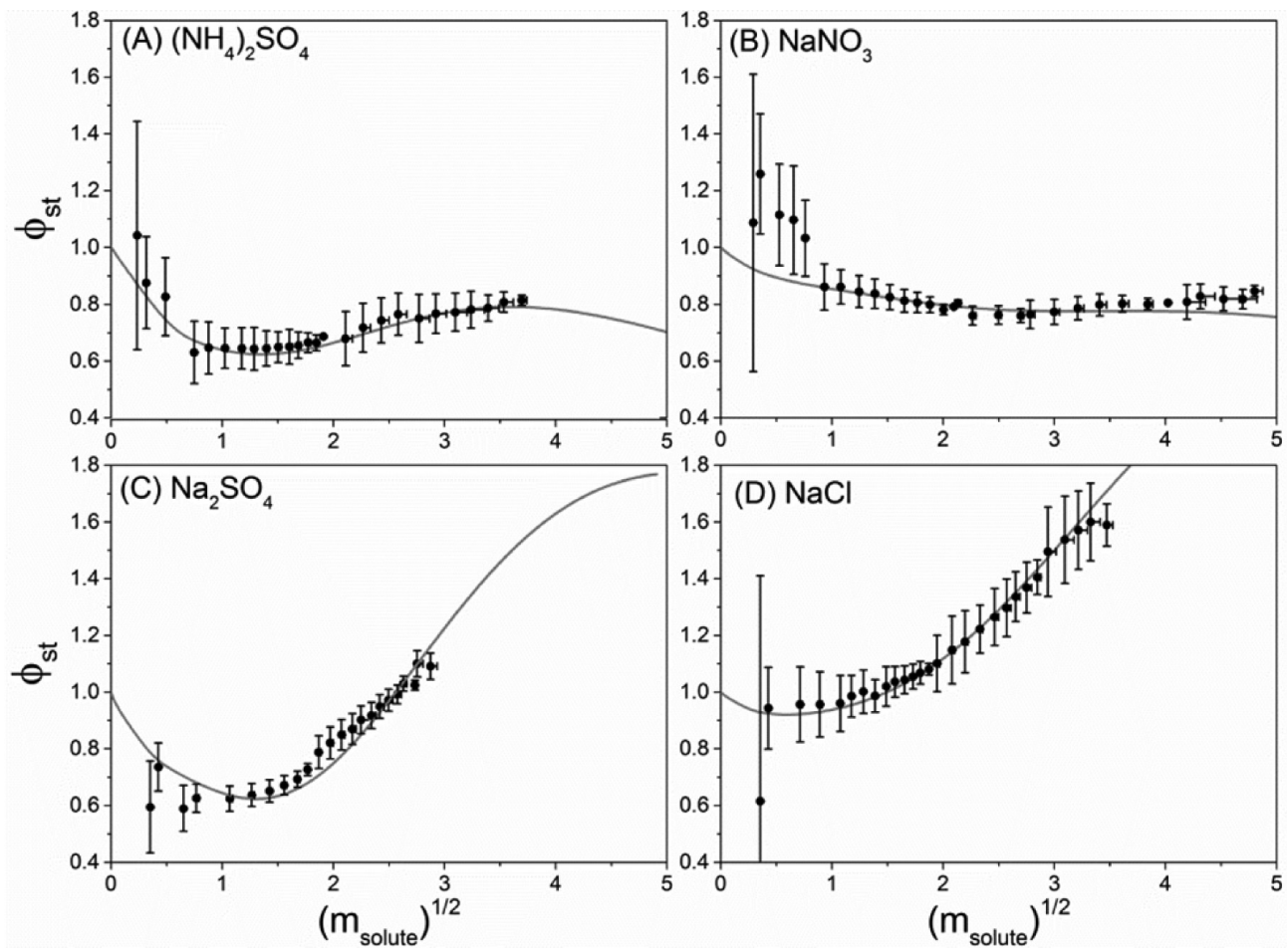

Figure 6. Dependence of osmotic coefficient on molality of solute $(\mathrm{mol} \mathrm{kg}-1)$ for $\left(\mathrm{NH}_{4}\right)_{2} \mathrm{SO}_{4}, \mathrm{NaNO}_{3}, \mathrm{Na}_{2} \mathrm{SO}_{4}$, and $\mathrm{NaCl}$ (panels A-D). Symbols: filled circles, experimental data; solid lines, calculation from the E-AIM model.

uncertainties attributed to measurements at these molalities are conservative. Deviations are typically $<0.02$ in osmotic coefficient for the $\left(\mathrm{NH}_{4}\right)_{2} \mathrm{SO}_{4}, \mathrm{NaNO}_{3}$, and $\mathrm{NaCl}$ systems, comparable to previous measurements (see, for example, the comparisons of predictions and measurements of osmotic coefficients in the work by Clegg et al. ${ }^{47}$ ). Larger discrepancies are observed for $\mathrm{Na}_{2} \mathrm{SO}_{4}$ at intermediate concentrations and these have already been discussed above.

To better illustrate the agreement between the experimental results and simulations from the E-AIM model, Figure 7 provides a comparison between the measured and modeled $n_{\text {water }} / n_{\text {solute }}$ ratios for the four inorganic systems, spanning the 


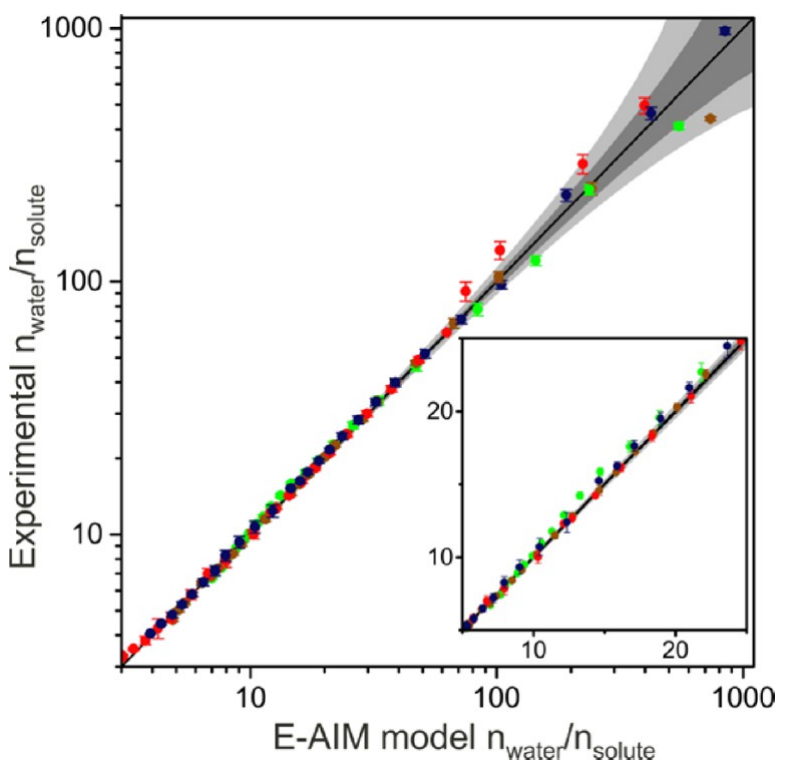

Figure 7. Correlation plot showing the experimentally measured and E-AIM predicted values for $n_{\text {water }} / n_{\text {solute }}$, displayed on a logarithmic scale in the main graph and on a linear scale in the inset. Symbols: green, $\left(\mathrm{NH}_{4}\right)_{2} \mathrm{SO}_{4}$; red, $\mathrm{NaNO}_{3}$; blue, $\mathrm{Na}_{2} \mathrm{SO}_{4}$; purple, $\mathrm{NaCl}$; solid line, 1:1 correlation line;. Gray shading: uncertainty on $n_{\text {water }} / n_{\text {solute }}$ for $\left(\mathrm{NH}_{4}\right)_{2} \mathrm{SO}_{4}$, corresponding to an error in $a_{\mathrm{w}}$ of \pm 0.001 (dark gray) and 0.002 (light gray).

range from just 3 water molecules per ion pair up to 1000 . For each point in the plot, $n_{\text {water }} / n_{\text {solute }}$ was calculated with the EAIM model at the exact $a_{\mathrm{w}}$ value of the experimental data point. For $n_{\text {water }} / n_{\text {solute }}$ values up to about 100 (corresponding to $a_{\mathrm{w}}$ of up to about 0.98 , depending on the salt), all the points lie close to the $1: 1$ line, thus revealing a very good agreement of the experimental results with the E-AIM model calculations. For $n_{\text {water }} / n_{\text {solute }}>100$, the points appear a little more scattered. This is due to the fact that at very high $a_{\mathrm{w}}$ values, even a slight variation in water activity results in a significant variation in the calculated water moles values, with the hygroscopic growth curve extremely steep in this region. As an example, the highest measured data point for $\left(\mathrm{NH}_{4}\right)_{2} \mathrm{SO}_{4}$ can be considered: the measured $a_{\mathrm{w}}$ is 0.997 and it corresponds to $799 n_{\text {water }} / n_{\text {solute }}$ calculated with the E-AIM model; if an uncertainty of \pm 0.001 in $a_{\mathrm{w}}$ is considered, the calculated $n_{\text {water }} / n_{\text {solute }}$ values are 585 and 1236 for water activity values of 0.996 and 0.998 , respectively. To show the effect of such a small uncertainty on water activity, in Figure 7 the uncertainty on the calculated $n_{\text {water }} / n_{\text {solute }}$ for ammonium sulfate is represented with dark and light gray envelopes if an error of \pm 0.001 and \pm 0.002 in $a_{\mathrm{w}}$ is considered, respectively. These envelopes become increasingly large when the amount of absorbed water increases because of the steepness of the hygroscopic growth curve in that region.

3.3. Sensitivity to Small Changes in Chemical Composition. Hygroscopic growth measurements on mixtures of $\mathrm{NaCl}$ and $\left(\mathrm{NH}_{4}\right)_{2} \mathrm{SO}_{4}$ were also taken to evaluate the sensitivity of the experimental method to small changes in the chemical composition of the aerosol droplets. Three different $\left(\mathrm{NH}_{4}\right)_{2} \mathrm{SO}_{4} / \mathrm{NaCl}$ mass ratios were considered (50/50, 90/10, and $95 / 5)$ and the $\mathrm{mfs}$ and $\mathrm{GF}_{\mathrm{r}}$ vs $a_{\mathrm{w}}$ experimental curves (circles) are compared with simulations from the E-AIM model (dashed lines) in Figure 8. For the calculation of growth factors of these mixtures, the reference dry state is considered to be a solid particle made of nonmixed crystalline ammonium sulfate and sodium chloride. The dry density is calculated estimating the dry volumes separately for $\mathrm{NaCl}$ and $\left(\mathrm{NH}_{4}\right)_{2} \mathrm{SO}_{4}$ and calculating the ratio between the total mass and the total volume of the two dry salts.

The experimental results show an overall good agreement with the curves predicted by the E-AIM model for all three mixtures considered, both for the $\mathrm{mfs}$ and for the $\mathrm{GF}_{\mathrm{r}}$ curves. The obtained $\mathrm{mfs}$ vs $a_{\mathrm{w}}$ plot (Figure 8A) shows that it is possible to successfully characterize the different hygroscopic behaviors of the $90 / 10$ and $95 / 5$ mixtures up to about $a_{\mathrm{w}}=$ 0.93. Above this value, the trends for the $90 / 10$ and $95 / 5$
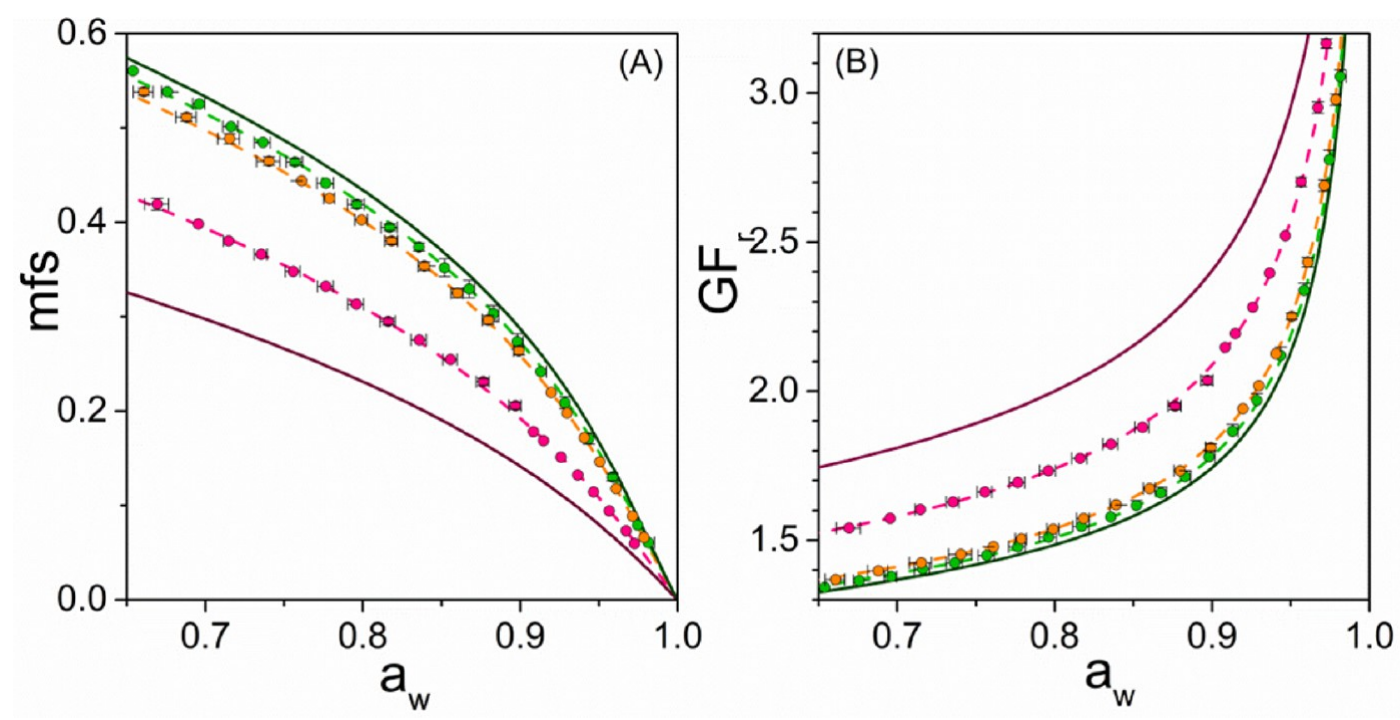

Figure 8. $\mathrm{mfs}$ vs $a_{\mathrm{w}}$ (panel A) and $\mathrm{GF}_{\mathrm{r}}$ vs $a_{\mathrm{w}}$ (panel B) plots for $\left(\mathrm{NH}_{4}\right)_{2} \mathrm{SO}_{4}$ and $\mathrm{NaCl}$ mixtures at different mass ratios, represented in the form $\left(\mathrm{NH}_{4}\right)_{2} \mathrm{SO}_{4} / \mathrm{NaCl}$. Symbols: filled circles, experimental data; solid lines, calculations from the E-AIM model for pure $\left(\mathrm{NH}_{4}\right)_{2} \mathrm{SO}_{4}$ and $\mathrm{NaCl}$; dashed lines, calculations from the E-AIM model for the mixtures. From top to bottom in (A) (bottom to top in (B)), the lines/symbols are for pure $\mathrm{NaCl}$ (violet), 50/50 ratio (pink), 90/10 ratio (orange), 95/5 ratio (light green), pure $\left(\mathrm{NH}_{4}\right)_{2} \mathrm{SO}_{4}$ (dark green). Note: error bars are smaller than the data point when not shown. 
mixtures become very similar: the difference between the two curves is less than $0.01 \mathrm{mfs}$, and discriminating between them is not possible. When the experimental results are plotted as $\mathrm{GF}_{\mathrm{r}}$ vs $a_{\mathrm{w}}$ (Figure $8 \mathrm{~B}$ ), the predicted curves for the same two mass ratios differ by 0.021 in $\mathrm{GF}_{\mathrm{r}}$ at $a_{\mathrm{w}}=0.65$ and by 0.058 in $\mathrm{GF}_{\mathrm{r}}$ at $a_{\mathrm{w}}=0.95$; in this range, it was possible to discriminate between their $\mathrm{GF}_{\mathrm{r}}$ trends with the EDB measurements. For higher water activity values, the hygroscopic growth curve becomes steep and differences between the two trends are not discernible. The comparison could not be carried out for the ratio $n_{\text {water }} / n_{\text {solute }}$ because the curves predicted by the E-AIM model for the 90/ 10 and 95/5 mixtures are both essentially indistinguishable from that of ammonium sulfate.

These results show that it is possible with this technique to detect variations in the hygroscopicity of solutions with only slight differences in chemical compositions, down to a $5 \%$ difference on a mass basis for mixtures of $\mathrm{NaCl}$ and $\left(\mathrm{NH}_{4}\right)_{2} \mathrm{SO}_{4}$. In the case of different mixtures, the minimum detectable variation would depend on the nature of their components: greater discrimination would be achieved if the individual pure components were to much more dissimilar hygroscopic properties.

3.4. Sensitivity to the Value of the Mass Accommodation Coefficient. The sensitivity of these hygroscopicity measurements to variations in the mass accommodation coefficient $\left(\alpha_{M}\right)$ was also investigated. The mass accommodation coefficient represents the fraction of water molecules that is absorbed into the droplet bulk on collision with the surface, considered equivalent to the evaporation coefficient by the principle of microscopic reversibility. In the literature, measurements of the mass accommodation coefficient have been performed with a number of different techniques, resulting in a considerable range of different $\alpha_{M}$ values. ${ }^{46,50,51} \alpha_{M}$ contributes to the mass transition correction factor $\left(\beta_{M}\right.$, eq 5$)$ in the kinetics model used here. Up to this point we have assumed that $\alpha_{\mathrm{M}}$ has a value equal to 1 , in agreement with previous studies which have reported the value of $\alpha_{M}$ for water accommodating/evaporation from a water surface. ${ }^{23,46,52}$ Similar to $\alpha_{M}$, the thermal accommodation coefficient $\left(\alpha_{T}\right)$ indicates the efficiency with which a colliding water molecule is able to transfer energy to the droplet and is included in the expression for $\beta_{T}$, the heat transition correction factor. For all the results presented in the previous sections and for the analysis discussed here, $\alpha_{T}$ was maintained constant at 1 , in agreement with literature studies on aqueous solution droplets, ${ }^{51,53}$ and the possible effects of its variation have not been investigated.

In previous work, ${ }^{34}$ we have examined the influence of the uncertainty in $\alpha_{M}$ on the evaporation kinetics profiles of aqueous solutions. We have shown that the evaporation kinetics measurements for droplets with radii larger than $5 \mu \mathrm{m}$ are insensitive to variations in $\alpha_{M}$ when $>0.05$ when the uncertainties resulting from the remaining thermophysical parameters and the experimental conditions are considered. Here the influence of $\alpha_{M}$ on the obtained hygroscopic growth curve of $\mathrm{NaCl}$ expressed in terms of $n_{\text {water }} / n_{\text {solute }}$ for $\mathrm{NaCl}$ is considered over the entire range of $\mathrm{RH}$ investigated in this work (from $50 \%$ to above $99 \% \mathrm{RH}$ ). In Figure 9, the black circles represent the original growth curve calculated with $\alpha_{M}=$ 1 , whereas the gray open circles represent the $n_{\text {water }} / n_{\text {solute }}$ for the same evaporating droplets data sets but with the analysis performed assuming $\alpha_{M}=0.1$. A slight shift in the water activity calculated with eq 5 can be observed when the value of the

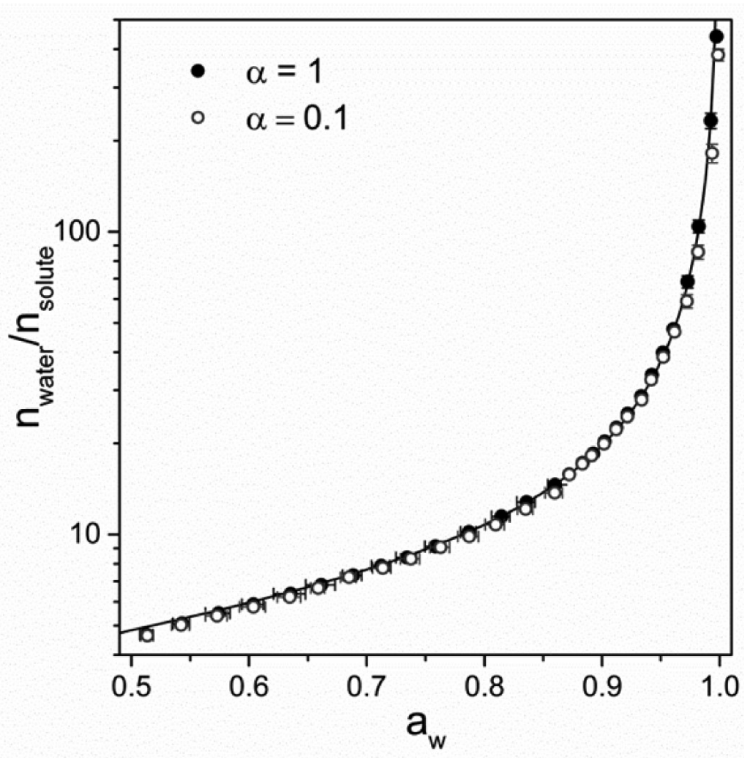

Figure 9. $n_{\text {water }} / n_{\text {solute }}$ vs $a_{\mathrm{w}}$ growth curve on a logarithmic scale for $\mathrm{NaCl}$ obtained when two different values for the mass accommodation coefficient were used in data processing (eq 5). Symbols: circles, experimental obtained with $\alpha_{M}=1$; open circles, experimental obtained with $\alpha_{M}=0.1$; solid line, prediction from the E-AIM model.

mass accommodation coefficient is varied, especially for $a_{\mathrm{w}}$ values above 0.95 where the growth curve becomes very steep. Nevertheless, the two curves can be considered to be very similar within the experimental errors. The superior agreement of the curve calculated with $\alpha_{M}=1$ (black circles) and the prediction from the E-AIM model (black solid line) at very high $a_{\mathrm{w}}$, together with the very good results obtained for all the aerosol systems presented in sections 3.2 and 3.3, suggests that assuming a value of $\alpha_{M}=1$ most accurately characterizes the mass transport behavior observed in the evaporating droplets for all of the binary and ternary systems studied here.

\section{CONCLUSIONS}

Using the comparative kinetics technique, we have shown that equilibrium hygroscopic growth measurements can be made with typical accuracies in water activity of better than $< \pm 0.2 \%$ at water activities $>0.9$ (see, for example, Figure 7 ) and $\sim \pm 1 \%$ below $80 \% \mathrm{RH}$. Conventional instruments report growth under subsaturated conditions with accuracies of $\pm 1 \%$ in $a_{\mathrm{w}}$ below $95 \% \mathrm{RH}$ and $\pm 0.1 \%$ for high-humidity instruments at $>99 \%$ $\mathrm{RH}^{14,16,30}$ In CCN activation measurements, the uncertainty in the critical supersaturation value is typically between $30 \%$ at supersaturations between 0.1 and $1 \%$, equivalent to uncertainties of 0.03 to $0.3 \%$ at $a_{\mathrm{w}}>0.99 .^{31}$ In addition, the largest uncertainties in diameter growth factor from this technique are of order $\sim 0.7 \%$ (see, for example, the points that have error bars larger than the point size in Figure 8); subsaturated growth measurements by conventional instruments have associated uncertainties of $\pm 5 \%$ with large interinstrument variabilities. $^{16,26}$ Indeed, the hygroscopic growth curves for mixed component aerosol containing $\left(\mathrm{NH}_{4}\right)_{2} \mathrm{SO}_{4} / \mathrm{NaCl}$ mass ratios of 90/10 and 95/5 shown in Figure 8 are clearly resolved: the difference between growth factors for these two systems varies from 0.02 at $65 \% \mathrm{RH}$ (at growth factors of $\sim 1.34$, i.e., a $1.5 \%$ difference) up to 0.07 at $98 \% \mathrm{RH}$ (at growth factors of $\sim 3.20$, 
i.e., a $2 \%$ difference). Such a small effect would unlikely be resolved in conventional instruments.

The instrument described here has some significant benefits for rapidly surveying the hygroscopic growth of laboratory generated aerosols of known composition or, indeed, samples from field measurements. Determinations of hygroscopic growth can be made over a wide range in water activity by measuring the time-dependent profiles of droplets evaporating into a selected sequence of RHs (potentially down to fully dry conditions and up to water activities greater than 0.99) with a similar level of accuracy and without particular refinement to address specific water activity ranges. The opportunity to measure hygroscopic growth to such high water activity should provide an opportunity to address some of the challenges in resolving the discrepancies between determinations of $\kappa$ from measurements made under subsaturated and supersaturated conditions. An advantage of performing measurements on coarse mode particles ( $>5 \mu \mathrm{m}$ in diameter) is that the Kelvin component of the equilibrium response is negligible when compared with the solute component. Thus, the surface curvature component can be ignored, providing the most unambiguous route to accurate measurements of the solute effect. In addition, this approach yields growth curves in a few seconds starting from the limit of high water activity, particularly valuable for studying organic compounds of low solubility or high volatility by avoiding the complications that follow when changes in the particle-gas partitioning of the VOC/SVOC must be considered. Hygroscopic growth measurements can also be made over a wide temperature range from $<250$ to $>320 \mathrm{~K}$ although we focus on ambient temperatures in this publication. Although not appropriate for direct field measurements on accumulation mode particles, the technique can be used to characterize samples with volumes of only a few tens of microliters, the minimum volume required to load the piezoelectric droplet-on-demand generators used to deliver droplets to the electrodynamic balance. Benefiting from these advantages, studies are underway to provide accurate measurements of hygroscopic growth for a wide range of organic components found in ambient aerosol containing disparate functional groups and containing multiple functionalities in the same solute molecule.

\section{ASSOCIATED CONTENT}

\section{S Supporting Information}

The Supporting Information is available free of charge on the ACS Publications website at DOI: 10.1021/acs.jpca.6b04194.

Schematics of the procedure for the retrieval of hygroscopic growth curves from evaporation profiles (PDF)

\section{AUTHOR INFORMATION}

\section{Corresponding Author}

*Jonathan P. Reid. E-mail: j.p.reid@bristol.ac.uk. Telephone: +441173317388.

\section{Notes}

The authors declare no competing financial interest.

The experimental data presented in the figures are provided through the University of Bristol data repository at Reid, J. P. (2015): DOI: 10.5523/bris.h8igni7g424s19a8ab3boyjb5.

\section{ACKNOWLEDGMENTS}

R.E.H.M., J.P.R., and S.L.C. acknowledge support from the Natural Environment Research Council through grant NE/ N006801/1. G.R. acknowledges the Italian Ministry of Education for the award of a Ph.D. studentship.

\section{REFERENCES}

(1) Dusek, U.; Frank, G. P.; Hildebrandt, L.; Curtius, J.; Schneider, J.; Walter, S.; Chand, D.; Drewnick, F.; Hings, S.; Jung, D.; et al. Size Matters More than Chemistry for Cloud-Nucleating Ability of Aerosol Particles. Science 2006, 312 (5778), 1375-1378.

(2) Topping, D.; Connolly, P.; McFiggans, G. Cloud Droplet Number Enhanced by Co-Condensation of Organic Vapours. Nat. Geosci. 2013, 6, 443-446.

(3) Haddrell, A. E.; Davies, J. F.; Reid, J. P. Dynamics of Particle Size on Inhalation of Environmental Aerosol and Impact on Deposition Fraction. Environ. Sci. Technol. 2015, 49 (24), 14512-14521.

(4) Ervens, B. Influence of Water-Soluble Organic Carbon on Cloud Drop Number Concentration. J. Geophys. Res. 2005, 110 (D18), D18211.

(5) Clegg, S. L.; Brimblecombe, P.; Wexler, A. S. Thermodynamic Model of the System $\mathrm{H}^{+}-\mathrm{NH}_{4}{ }^{+}-\mathrm{SO}_{4}{ }^{2-}-\mathrm{NO}_{3}{ }^{-}-\mathrm{H}_{2} \mathrm{O}$ at Tropospheric Temperatures. J. Geophys. Res. 1998, 102 (12), 2137-2154.

(6) Wexler, A. S.; Clegg, S. L. Atmospheric Aerosol Models for Systems Including the Ions $\mathrm{H}^{+}, \mathrm{NH}_{4}^{+}, \mathrm{Na}^{+}, \mathrm{SO}_{4}{ }^{2-}, \mathrm{NO}_{3}{ }^{-}, \mathrm{Cl}^{-}, \mathrm{Br}^{-}$, and $\mathrm{H}_{2} \mathrm{O}$. J. Geophys. Res. 2002, 107 (D14), 4207.

(7) Topping, D. O.; McFiggans, G. B.; Coe, H. A Curved MultiComponent Aerosol Hygroscopicity Model Framework: Part 2 Including Organics Compounds. Atmos. Chem. Phys. 2005, 5, 12231242.

(8) Topping, D. O.; Mcfiggans, G. B.; Coe, H. And Physics A Curved Multi-Component Aerosol Hygroscopicity Model Framework: Part 1 - Inorganic Compounds. Atmos. Chem. Phys. 2005, 5, 1205-1222.

(9) Zuend, A.; Marcolli, C.; Booth, A. M.; Lienhard, D. M.; Soonsin, V.; Krieger, U. K.; Topping, D. O.; McFiggans, G.; Peter, T.; Seinfeld, J. H. New and Extended Parameterization of the Thermodynamic Model AIOMFAC: Calculation of Activity Coefficients for OrganicInorganic Mixtures Containing Carboxyl, Hydroxyl, Carbonyl, Ether, Ester, Alkenyl, Alkyl, and Aromatic Functional Groups. Atmos. Chem. Phys. 2011, 11 (17), 9155-9206.

(10) Zuend, A.; Marcolli, C.; Luo, B. P.; Peter, T. A Thermodynamic Model of Mixed Organic-Inorganic Aerosols to Predict Activity Coefficients. Atmos. Chem. Phys. 2008, 8, 4559-4593.

(11) Kreidenweis, S. M.; Petters, M. D.; DeMott, P. J. SingleParameter Estimates of Aerosol Water Content. Environ. Res. Lett. 2008, 3, 035002.

(12) Petters, M. D.; Kreidenweis, S. M. A Single Parameter Representation of Hygroscopic Growth and Cloud Condensation Nucleus Activity. Atmos. Chem. Phys. 2007, 7, 1961-1971.

(13) Chang, R. Y.-W.; Slowik, J. G.; Shantz, N. C.; Vlasenko, A.; Liggio, J.; Sjostedt, S. J.; Leaitch, W. R.; Abbatt, J. P. D. The Hygroscopicity Parameter $(\kappa)$ of Ambient Organic Aerosol at a Field Site Subject to Biogenic and Anthropogenic Influences: Relationship to Degree of Aerosol Oxidation. Atmos. Chem. Phys. 2010, 10 (11), 5047-5064.

(14) Duplissy, J.; DeCarlo, P. F.; Dommen, J.; Alfarra, M. R.; Metzger, A.; Barmpadimos, I.; Prevot, A. S. H.; Weingartner, E.; Tritscher, T.; Gysel, M.; et al. Relating Hygroscopicity and Composition of Organic Aerosol Particulate Matter. Atmos. Chem. Phys. 2011, 11, 1155-1165.

(15) Rickards, A. M. J.; Miles, R. E. H.; Davies, J. F.; Marshall, F. H.; Reid, J. P. Measurements of the Sensitivity of Aerosol Hygroscopicity and the $\kappa$ Parameter to the $\mathrm{O} / \mathrm{C}$ Ratio. J. Phys. Chem. A 2013, 117 (51), 14120-14131.

(16) Good, N.; Topping, D. O.; Duplissy, J.; Gysel, M.; Meyer, N. K.; Metzger, a.; Turner, S. F.; Baltensperger, U.; Ristovski, Z.; Weingartner, E.; et al. Widening the Gap between Measurement and 
Modelling of Secondary Organic Aerosol Properties? Atmos. Chem. Phys. 2010, 10, 2577-2593.

(17) Petters, M. D.; Kreidenweis, S. M. A Single Parameter Representation of Hygroscopic Growth and Cloud Condensation Nucleus Activity - Part 3: Including Surfactant Partitioning. Atmos. Chem. Phys. 2013, 13 (2), 1081-1091.

(18) Pajunoja, A.; Lambe, A. T.; Hakala, J.; Rastak, N.; Cummings, M. J.; Brogan, J. F.; Hao, L.; Paramonov, M.; Hong, J.; Prisle, N. L.; et al. Adsorptive Uptake of Water by Semisolid Secondary Organic Aerosols. Geophys. Res. Lett. 2014, 42, 3063-3068.

(19) You, Y.; Smith, M. L.; Song, M.; Martin, S. T.; Bertram, A. K. Liquid-liquid Phase Separation in Atmospherically Relevant Particles Consisting of Organic Species and Inorganic Salts. Int. Rev. Phys. Chem. 2014, 33, 43-77.

(20) Topping, D.; Barley, M.; McFiggans, G. Including Phase Separation in a Unified Model to Calculate Partitioning of Vapours to Mixed Inorganic-organic Aerosol Particles. Faraday Discuss. 2013, 165, 273.

(21) Sareen, N.; Schwier, A. N.; Lathem, T. L.; Nenes, A.; McNeill, V. F. Surfactants from the Gas Phase May Promote Cloud Droplet Formation. Proc. Natl. Acad. Sci. U. S. A. 2013, 110 (8), 2723-2728.

(22) Nozière, B.; Baduel, C.; Jaffrezo, J.-L. The Dynamic Surface Tension of Atmospheric Aerosol Surfactants Reveals New Aspects of Cloud Activation. Nat. Commun. 2014, 5, 1-7.

(23) Davies, J. F.; Miles, R. E. H.; Haddrell, A. E.; Reid, J. P. Temperature Dependence of the Vapor Pressure and Evaporation Coefficient of Supercooled Water. J. Geophys. Res. Atmos. 2014, 119 (18), 10931-10940.

(24) Vehkamäki, H.; Riipinen, I. Thermodynamics and Kinetics of Atmospheric Aerosol Particle Formation and Growth. Chem. Soc. Rev. 2012, 41, 5160.

(25) Kolb, C. E.; Cox, R. A.; Abbatt, J. P. D.; Ammann, M.; Davis, E. J.; Donaldson, D. J.; Garrett, B. C.; George, C.; Griffiths, P. T.; Hanson, D. R.; et al. An Overview of Current Issues in the Uptake of Atmospheric Trace Gases by Aerosols and Clouds. Atmos. Chem. Phys. 2010, 10 (21), 10561-10605.

(26) Suda, S. R; Petters, M. D. Accurate Determination of Aerosol Activity Coefficients at Relative Humidities up to $99 \%$ Using the Hygroscopicity Tandem Differential Mobility Analyzer Technique. Aerosol Sci. Technol. 2013, 47 (9), 991-1000.

(27) Krieger, U. K.; Marcolli, C.; Reid, J. P. Exploring the Complexity of Aerosol Particle Properties and Processes Using Single Particle Techniques. Chem. Soc. Rev. 2012, 41 (19), 6631.

(28) Wex, H.; Petters, M. D.; Carrico, C. M.; Hallbauer, E.; Massling, A.; McMeeking, G. R.; Poulain, L.; Wu, Z.; Kreidenweis, S. M.; Stratmann, F. Towards Closing the Gap between Hygroscopic Growth and Activation for Secondary Organic Aerosol: Part 1 - Evidence from Measurements. Atmos. Chem. Phys. 2009, 9, 3987-3997.

(29) Walker, J. S.; Wills, J. B.; Reid, J. P.; Wang, L.; Topping, D. O.; Butler, J. R; Zhang, Y.-H. Direct Comparison of the Hygroscopic Properties of Ammonium Sulfate and Sodium Chloride Aerosol at Relative Humidities Approaching Saturation. J. Phys. Chem. A 2010, 114 (48), 12682-12691.

(30) McFiggans, G.; Artaxo, P.; Baltensperger, U.; Coe, H.; Facchini, M. C.; Feingold, G.; Fuzzi, S.; Gysel, M.; Laaksonen, A.; Lohmann, U.; et al. The Effect of Physical and Chemical Aerosol Properties on Warm Cloud Droplet Activation. Atmos. Chem. Phys. 2006, 6, 25932649.

(31) Rose, D.; Frank, G. P.; Dusek, U.; Gunthe, S. S.; Andreae, M. O.; Pöschl, U. Calibration and Measurement Uncertainties of a Continuous-Flow Cloud Condensation Nuclei Counter (DMTCCNC): CCN Activation of Ammonium Sulfate and Sodium Chloride Aerosol Particles in Theory and Experiment. Atmos. Chem. Phys. 2008, 8, 1153-1179.

(32) Davies, J. F.; Haddrell, A. E.; Rickards, A. M. J.; Reid, J. P. Simultaneous Analysis of the Equilibrium Hygroscopicity and Water Transport Kinetics of Liquid Aerosol. Anal. Chem. 2013, 85 (12), 5819-5826.
(33) Davies, J. F.; Haddrell, A. E.; Reid, J. P. Time-Resolved Measurements of the Evaporation of Volatile Components from Single Aerosol Droplets. Aerosol Sci. Technol. 2012, 46 (6), 666-677.

(34) Davies, J. F.; Haddrell, A. E.; Miles, R. E. H.; Bull, C. R.; Reid, J. P. Bulk, Surface, and Gas-Phase Limited Water Transport in Aerosol. J. Phys. Chem. A 2012, 116 (45), 10987-10998.

(35) Heinisch, C.; Wills, J. B.; Reid, J. P.; Tschudi, T.; Tropea, C. Temperature Measurement of Single Evaporating Water Droplets in a Nitrogen Flow Using Spontaneous Raman Scattering. Phys. Chem. Chem. Phys. 2009, 11 (42), 9720-9728.

(36) Glantschnig, W. J.; Chen, S. H. Light Scattering from Water Droplets in the Geometrical Optics Approximation. Appl. Opt. 1981, 20 (14), 2499-2509.

(37) Liu, Y.; Daum, P. H. Relationship of Refractive Index to Mass Density and Self-Consistency of Mixing Rules for Multicomponent Mixtures like Ambient Aerosols. J. Aerosol Sci. 2008, 39 (11), 974986.

(38) Cotterell, M.; Mason, B. J.; Preston, T. C.; Orr-Ewing, A.; Reid, J. P. Optical Extinction Efficiency Measurements on Fine and Accumulation Mode Aerosol Using Single Particle Cavity RingDown Spectroscopy. Phys. Chem. Chem. Phys. 2015, 17, 15843-15856.

(39) Clegg, S. L.; Wexler, A. S. Densities and Apparent Molar Volumes of Atmospherically Important Electrolyte Solutions. 1. The Solutes $\mathrm{H}_{2} \mathrm{SO}_{4}, \mathrm{HNO}_{3}, \mathrm{HCl}, \mathrm{Na}_{2} \mathrm{SO}_{4}, \mathrm{NaNO}_{3}, \mathrm{NaCl},\left(\mathrm{NH}_{4}\right)_{2} \mathrm{SO}_{4}$, $\mathrm{NH}_{4} \mathrm{NO}_{3}$ and $\mathrm{NH}_{4} \mathrm{Cl}$ from 0 to $50{ }^{\circ} \mathrm{C}$, Including Extrapolations to Very Low Temperature and to the Pure Liquid State, and $\mathrm{NaHSO}_{4}$, $\mathrm{NaOH}$, and $\mathrm{NH}_{3}$ at $25{ }^{\circ} \mathrm{C}$. J. Phys. Chem. A 2011, 115 (15), 33933460.

(40) Janz, G. J. Thermodynamic and Transport Properties of Molten Salts: Correlation Equations for Critically Evaluated Density, Surface Tension, Electrical Conductance, and Viscosity Data. J. Phys. Chem. Ref. Data 1988, 17 (Supplement 2), 309 pages. http://www.nist.gov/ data/PDFfiles/jpcrdS2Vol17.pdf

(41) Lide, D. R. CRC Handbook of Chemistry and Physics, 85th ed.; CRC Press: Boca Raton, FL, 2005.

(42) Kulmala, M.; Vesala, T.; Wagner, P. E. An Analytical Expression For the Rate of Binary Condensational Particle Growth. Proc. R. Soc. London, Ser. A 1993, 441 (1913), 589-605.

(43) Hopkins, R. J.; Reid, J. P. Evaporation of Ethanol/water Droplets: Examining the Temporal Evolution of Droplet Size, Composition and Temperature. J. Phys. Chem. A 2005, 109 (35), 7923-7931.

(44) Nielsen, J. K.; Maus, C.; Rzesanke, D.; Leisner, T. Charge Induced Stability of Water Droplets in Subsaturated Environment. Atmos. Chem. Phys. 2011, 11 (5), 2031-2037.

(45) Miles, R. E. H.; Knox, K. J.; Reid, J. P.; Laurain, A. M. C.; Mitchem, L. Measurements of Mass and Heat Transfer at a Liquid Water Surface during Condensation or Evaporation of a Subnanometer Thickness Layer of Water. Phys. Rev. Lett. 2010, 105 (11), 116101.

(46) Miles, R. E. H.; Reid, J. P.; Riipinen, I. Comparison of Approaches for Measuring the Mass Accommodation Coefficient for the Condensation of Water and Sensitivities to Uncertainties in Thermophysical Properties. J. Phys. Chem. A 2012, 116 (44), 1081010825.

(47) Clegg, S. L.; Brimblecombe, P.; Wexler, A. S. Thermodynamic Model of the System $\mathrm{H}^{+}-\mathrm{NH}_{4}{ }^{+}-\mathrm{Na}^{+}-\mathrm{SO}_{4}{ }^{2-}-\mathrm{NO}_{3}{ }^{-}-\mathrm{Cl}^{-}-\mathrm{H}_{2} \mathrm{O}$ at 298.15 K. J. Phys. Chem. A 1998, 102 (12), 2155-2171.

(48) Archer, D. G. Thermodynamic Properties of the $\mathrm{NaCl}+\mathrm{H}_{2} \mathrm{O}$ System. II. Thermodynamic Properties of $\mathrm{NaCl}_{(\mathrm{aq})}, \mathrm{NaCl} \cdot 2 \mathrm{H}_{2} \mathrm{O}_{(\mathrm{cr})}$, and Phase Equilibria. J. Phys. Chem. Ref. Data 1992, 21 (4), 793.

(49) Clegg, S. L.; Brimblecombe, P.; Liang, Z.; Chan, C. K. Thermodynamic Properties of Aqueous Aerosols to High Supersaturation: II-A Model of the System $\mathrm{Na}^{+}-\mathrm{Cl}^{-}-\mathrm{NO}_{3}^{-}-\mathrm{SO}_{4}{ }^{2-}-\mathrm{H}_{2} \mathrm{O}$ at 298.15 K. Aerosol Sci. Technol. 1997, 27 (3), 345-366.

(50) Davidovits, P.; Kolb, C. E.; Williams, L. R.; Jayne, J. T.; Worsnop, D. R. Mass Accommodation and Chemical Reactions at Gas-Liquid Interfaces. Chem. Rev. 2006, 106, 1323-1354. 
(51) Winkler, P. M.; Vrtala, A.; Rudolf, R.; Wagner, P. E.; Riipinen, I.; Vesala, T.; Lehtinen, K. E. J.; Viisanen, Y.; Kulmala, M. Condensation of Water Vapor: Experimental Determination of Mass and Thermal Accommodation Coefficients. J. Geophys. Res. 2006, 111 (D19), D19202.

(52) Julin, J.; Shiraiwa, M.; Miles, R. E. H.; Reid, J. P.; Pöschl, U.; Riipinen, I. Mass Accommodation of Water: Bridging the Gap between Molecular Dynamics Simulations and Kinetic Condensation Models. J. Phys. Chem. A 2013, 117 (2), 410-420.

(53) Li, Y. Q.; Davidovits, P.; Kolb, C. E.; Worsnop, D. R. Mass and Thermal Accommodation Coefficients of $\mathrm{H}_{2} \mathrm{O}(\mathrm{g})$ on Liquid Water as a Function of Temperature. J. Phys. Chem. A 2001, 105 (47), 1062710634. 